\title{
Fracionamento de carboidratos e degradabilidade ruminal da cana-de-açúcar tratada com óxido de cálcio
}

\author{
[Fractioning Fractioning of carbohydrates and rumen degradability of sugar cane \\ treated with calcium oxide] \\ C.O. Romão ${ }^{1}$, G.G.P. Carvalho $^{2}$, V.M. Leite $^{2}$, A.S. Santos $^{3}$, D.M.T. Chagas $^{4}$, O.L. Ribeiro ${ }^{2}$, \\ L.F.B. Pinto ${ }^{2}$, R.L. Oliveira ${ }^{2}$ \\ ${ }^{1}$ Aluno de pós-graduação - Universidade Federal da Bahia - Salvador, BA \\ ${ }^{2}$ Universidade Federal da Bahia - Salvador, BA \\ ${ }^{3}$ Aluna de graduação - Universidade Federal da Bahia - Salvador, BA \\ ${ }^{4}$ Aluna de pós-graduação - Universidade Estadual do Sudoeste da Bahia - Vitória da Conquista, BA
}

\begin{abstract}
RESUMO
Avaliaram-se o fracionamento de carboidratos e a degradabilidade in situ da matéria seca (MS) e da fibra em detergente neutro (FDN) da cana-de-açúcar tratada com óxido de cálcio $(\mathrm{CaO})$. Foram testadas as porcentagens de $0 ; 0,75 ; 1,5 ; 2,25 ; 3,0 ; 3,75$ e 4,5\% de $\mathrm{CaO}$, e o material testemunha (cana-de-açúcar in natura) para a avaliação do fracionamento de carboidratos, e as porcentagens de $0 ; 1,5 ; 3,0$ e 4,5\% de $\mathrm{CaO}$ para a avaliação da degradabilidade in situ da MS e da FDN. O CaO foi adicionado em pó na canade-açúcar, em porcentagem da matéria natural, por 24 horas. A porcentagem de inclusão de CaO na canade-açúcar proporcionou valores mais baixos para teores de carboidratos totais (CT) comparados aos valores da cana-de-açúcar in natura. Observou-se crescimento linear das frações A+B1 e B2, e redução na fração $\mathrm{C}$ da cana-de-açúcar em função da porcentagem de $\mathrm{CaO}$. Os maiores valores de fração insolúvel potencialmente degradável da MS e menores de fração indigestível (Ip) da FDN foram observados na cana-de-açúcar com 3,0 e 4,5\% de $\mathrm{CaO}$. A adição de 3,0 e 4,5\% de $\mathrm{CaO}$ na cana-de-açúcar promove diminuição da fração indigestível dos carboidratos e melhores taxas de degradação ruminal tanto da MS quanto da FDN.
\end{abstract}

Palavras-chave: cal, Saccharum officinarum, tratamento químico

\begin{abstract}
Were evaluated the fractioning of carbohydrates and in situ dry matter (DM) and neutral detergent fiber $(\mathrm{NDF})$ of sugarcane treated with calcium oxide ( $\mathrm{CaO}$ ). Levels $0,0.75,1.5,2.25,3.0,3.75$ and $4.5 \% \mathrm{CaO}$, and the material witness (sugarcane in nature) were tested for the assessment of fractioning of carbohydrates and levels 0, 1.5, 3.0 and 4.5\% CaO for the evaluation of in situ DM and NDF. The levels of $\mathrm{CaO}$ were added in powder form, as a percentage of natural matter in sugarcane for 24 hours. The inclusion levels of $\mathrm{CaO}$ in sugarcane showed lower values for the total carbohydrates (TC) when compared with sugarcane in natura. A linear growth of the fractions A $B 1$ and B2 was observed, as well as a decrease in $C$ fraction of sugarcane depending on the levels of CaO. The highest values of insoluble fraction potentially degradable in rumen and the lower values of NDF indigestible fraction (Ip) were observed in sugarcane with 3.0 and $4.5 \% \mathrm{CaO}$. The addition of 3.0 and $4.5 \% \mathrm{CaO}$ to sugarcane decreased the indigestible carbohydrates fraction and promotes better rates of ruminal degradation of both DM and NDF.
\end{abstract}

Keywords: lime, Saccharum officinarum, chemical treatment

Recebido em 15 de agosto de 2011

Aceito em 28 de agosto de 2012

E-mail: cromao@email.it 


\section{INTRODUÇÃO}

O tratamento químico com o objetivo de melhorar o valor nutritivo de volumosos é, ainda, objeto de estudos que procuram promover a redução do teor de fibra e o aumento na digestibilidade in vitro (Silva et al., 2005; Oliveira et al., 2006; Silva et al., 2006; Cavali, 2006; Balieiro Neto et al., 2007; Domingues et al., 2007; Teixeira Júnior et al., 2007) ou in situ (Macedo, 2010) da matéria seca da cana-deaçúcar por ocasião do tratamento com óxido de cálcio $(\mathrm{CaO})$. Contudo, os resultados ainda são incipientes frente aos desafios a serem vencidos em questões relacionadas ao fornecimento de alimento de boa qualidade a ruminantes em períodos estratégicos, tendo em vista que alguns trabalhos têm demonstrado baixa eficiência no tratamento químico.

A digestibilidade melhorada dos volumosos com a adição de aditivos alcalinos, relacionada à ação da hidrólise alcalina, beneficia o valor nutricional. Em um eventual sistema de alimentação, dietas balanceadas com volumosos tratados podem predispor animais a desempenhos semelhantes ao obtido com dietas de alta qualidade (Carvalho et al. 2009).

Dessa forma, este estudo foi realizado com o objetivo de identificar a porcentagem mais adequada de óxido de cálcio no tratamento da cana-de-açúcar, por meio da avaliação do fracionamento de carboidratos e da degradabilidade ruminal da matéria seca e da fibra em detergente neutro.

\section{MATERIAL E MÉTODOS}

A cana-de-açúcar utilizada foi a variedade RB 86-2480, produzida na Fazenda Experimental de São Gonçalo, da Universidade Federal da Bahia (UFBA). A colheita manual e montagem do experimento foram realizadas em março de 2010 , e as análises realizadas no período de abril e novembro de 2010

Inicialmente a cana-de-açúcar foi desintegrada e desta separado o material testemunha - cana-deaçúcar in natura. Em seguida, a cana-de-açúcar foi homogeneizada proporcionalmente com 0 ; 0,$75 ; 1,5 ; 2,25 ; 3,0 ; 3,75$ e $4,5 \%$ de $\mathrm{CaO}$ em pó, em porcentagem da matéria natural, dispostos em 28 montes, que permaneceram armazenados em temperatura ambiente por 24 horas após aplicação. Durante esse período foram aferidas as temperaturas a cada seis horas no interior dos montes (Tab. 1). Após as 24 horas de tratamento, amostras foram retiradas de cada monte e imediatamente refrigeradas em câmara fria para posteriores análises. Foram descongeladas e présecas em estufa de ventilação forçada $\left(55^{\circ} \mathrm{C}\right)$ por 72 horas e, em seguida, moídas a $1 \mathrm{~mm}$ em moinho de faca. $\mathrm{Na}$ sequência foram acondicionadas em embalagens plásticas, identificadas e armazenadas em local fresco para posterior análise química.

Tabela 1. Valores de temperatura obtidos nos montes de cana-de-açúcar tratada com óxido de cálcio $(\mathrm{CaO})$ avaliada em diferentes tempos após o tratamento

\begin{tabular}{cccccc}
\hline Teor de CaO na cana-de-açúcar & \multicolumn{5}{c}{ Tempo } \\
\cline { 2 - 6 }$(\% \mathrm{MN})$ & $\mathrm{Oh}$ & $6 \mathrm{~h}$ & $12 \mathrm{~h}$ & $18 \mathrm{~h}$ & $24 \mathrm{~h}$ \\
\hline & 32,7 & 33,0 & Temperatura ${ }^{\circ} \mathrm{C}$ \\
0 & 33,0 & 35,3 & 32,5 & 42,8 & 44,3 \\
1,75 & 37,8 & 38,0 & 33,0 & 38,3 & 41,5 \\
2,25 & 44,3 & 42,9 & 35,1 & 31,6 & 31,8 \\
3,0 & 51,6 & 48,9 & 36,5 & 31,8 & 30,0 \\
3,75 & 54,0 & 46,5 & 37,5 & 31,5 & 30,4 \\
4,5 & 63,0 & 48,4 & 37,6 & 32,3 & 30,0 \\
\hline
\end{tabular}

Temperatura mínima e máxima no dia da avaliação $\left(24^{\circ} \mathrm{C}\right.$ e $29^{\circ} \mathrm{C}$, respectivamente). 
Amostras da cana-de-açúcar com $0 ; 1,5 ; 3,0$ e $4,5 \%$ de $\mathrm{CaO}$, utilizadas na degradabilidade, foram previamente processadas em moinho de faca em peneira de $2 \mathrm{~mm}$ (NRC, 2001), acondicionadas em sacos de fibra sintética do tipo TNT, gramatura 100, na quantidade de, aproximadamente, 2,1g de MS/saco, a fim de manter uma relação próxima a $20 \mathrm{mg}$ de $\mathrm{MS} / \mathrm{cm}^{2}$ de área superficial do saco (Nocek, 1988). Os períodos de incubação corresponderam aos tempos de $0,12,24,48,72,96,120$ e 144 horas, sendo os sacos colocados em ordem inversa e em duplicata, para serem retirados todos ao mesmo tempo, promovendo, dessa forma, lavagem uniforme do material por ocasião da retirada do rúmen.

Após o período de incubação total de 144 horas, todos os sacos foram retirados do rúmen, lavados em água corrente até que esta se apresentasse limpa, procedendo-se, então, à secagem. A determinação da $\mathrm{MS}$ foi feita em estufa a $55^{\circ} \mathrm{C}$ por 72 horas. O resíduo obtido após essa etapa foi utilizado para as análises de FDN, segundo metodologias descritas por Silva e Queiroz (2002).

A percentagem de carboidratos totais (CT) foi obtida pela equação (Sniffen et al., 1992): $\mathrm{CT}=$ $100-(\% \mathrm{~PB}+\% \mathrm{EE}+\%$ cinza) $)$ Os carboidratos fibrosos (CF) foram obtidos a partir da FDN (FDN); os carboidratos não fibrosos (CNF), que correspondem às frações $\mathrm{A}+\mathrm{B} 1$, pela diferença entre os CT e a FDN (Hall, 2003); e a fração C, pela FDN indigestível após 144 horas de incubação in situ (Cabral et al., 2004). A fração B2, ou seja, a fração disponível da fibra, foi obtida pela diferença entre a FDN e a fração C.

Os dados de degradabilidade in situ da MS e FDN foram obtidos pela diferença de peso, encontrada, para cada componente, entre as pesagens efetuadas antes e após a incubação ruminal, e expressos em porcentagem.

Com o auxílio do programa estatístico SAS, foram calculadas as taxas de degradação da MS utilizando-se a equação proposta por Ørskov e
McDonald (1979): $\mathrm{Dt}=\mathrm{A}+\mathrm{B} \times(1-\mathrm{e}-\mathrm{ct}), \mathrm{em}$ que: $\mathrm{Dt}=$ fração degradada no tempo $\mathrm{t}(\%), \mathrm{A}=$ fração solúvel (\%); $\mathrm{B}=$ fração insolúvel potencialmente degradável $(\%) ; \mathrm{c}=$ taxa de degradação da fração B (h-1); e t= tempo (h). A degradabilidade da FDN foi estimada utilizando o modelo de Mertens e Loften (1980): Rt= B x ect, sendo $\mathrm{Rt}=$ fração degradada no tempo t; $\mathrm{B}$ e C = como definidas anteriormente.

Após os ajustes da equação de degradação da FDN, procedeu-se à padronização de frações, segundo a proposição de Waldo et al. (1972), conforme as equações: $\mathrm{BP}=\mathrm{B} /(\mathrm{B}+\mathrm{I}) \times 100$; $\mathrm{IP}=$ $\mathrm{I} /(\mathrm{B}+\mathrm{I}) \quad \mathrm{x}$ 100, em que: $\mathrm{BP}=$ fração potencialmente degradável padronizada $(\%)$; IP= fração indigestível padronizada $(\%)$; e B, I= como definidas anteriormente.

Os coeficientes não lineares A, B e c foram estimados por meio de procedimentos interativos de Gauss-Newton, sendo as médias comparadas por meio de intervalo de confiança com $95 \%$ de confiança.

A degradabilidade efetiva (DE) da MS no rúmen foi calculada utilizando o modelo: $\mathrm{DE}=\mathrm{A}+(\mathrm{B} \mathrm{x}$ $\mathrm{c} / \mathrm{c}+\mathrm{k})$, em que: $\mathrm{k}$ corresponde à taxa estimada de passagem das partículas no rúmen. Para a $\mathrm{DE}$ da FDN utilizou-se o modelo: $\mathrm{DE}=\mathrm{BP} \times \mathrm{c} /(\mathrm{c}+\mathrm{k})$, em que: BP é a fração potencialmente degradável (\%) padronizada.

Quanto ao fracionamento de carboidratos, o efeito da porcentagem de adição do $\mathrm{CaO}$ foram interpretados por meio de análise de variância e regressão a 5\% de probabilidade, e a comparação entre as porcentagens de $\mathrm{CaO}$ e a cana-de-açúcar in natura foi realizada conforme Dunnett (1955).

\section{RESULTADOS E DISCUSSÃO}

Verificaram-se que os teores de carboidratos totais (CT) da cana-de-açúcar nas porcentagens de inclusão de $\mathrm{CaO}$ de 1,5 a 4,5\% foram mais baixos $(\mathrm{P}<0,05)$ em relação ao da cana-de-açúcar in natura (Tab. 2). 
Tabela 2. Teores médios de carboidratos totais (CT), carboidratos não-fibrosos (A+B1), componentes da parede celular disponíveis, que correspondem às frações potencialmente degradáveis (B2) e fração indigestível da parede celular (C) da cana-de-açúcar in natura e tratada com óxido de cálcio

\begin{tabular}{|c|c|c|c|c|c|c|c|c|c|}
\hline \multirow[b]{2}{*}{ Item } & \multirow{2}{*}{$\begin{array}{l}\text { Cana-de- } \\
\text { açúcar in } \\
\text { natura }\end{array}$} & \multicolumn{7}{|c|}{ Óxido de cálcio na cana-de-açúcar (\% MN) } & \multirow[b]{2}{*}{$\mathrm{CV}(\%)$} \\
\hline & & 0 & 0,75 & 1,5 & 2,25 & 3,0 & 3,75 & 4,5 & \\
\hline $\mathrm{CT}^{1}$ & 95,1 & 93,3 & 93,1 & $90,6^{*}$ & $88,6^{*}$ & $88,9 *$ & $84,7 *$ & $83,6^{*}$ & 1,5 \\
\hline \multicolumn{10}{|c|}{ Frações de carboidratos (\% CT) } \\
\hline $\mathrm{A}+\mathrm{B} 1$ & 47,4 & $38,0 *$ & $42,5^{*}$ & 47,0 & $52,0 *$ & $53,2 *$ & $50,6^{*}$ & $49,8 *$ & 2,5 \\
\hline B2 & 32,2 & $40,0 *$ & $38,1^{*}$ & $37,3 *$ & $35,6 *$ & $38,3 *$ & $41,2 *$ & $42,5^{*}$ & 4,2 \\
\hline $\mathrm{C}$ & 20,4 & 22,0 & 19,4 & $15,7 *$ & $12,4^{*}$ & $8,5^{*}$ & $8,2 *$ & $7,7 *$ & 6,4 \\
\hline
\end{tabular}

${ }^{*}$ Médias seguidas com asterisco diferem da cana-de-açúcar in natura (testemunha) $(\mathrm{P}<0,05)$ pelo teste de Dunnett. ${ }^{1} \mathrm{Em} \%$ da matéria seca; $\mathrm{CV}=$ coeficiente de variação em \%; $\mathrm{MN}$ = matéria natural.

O teor de CT diminuiu de forma linear $(\mathrm{P}<0,05)$ em função dos níveis de $\mathrm{CaO}$ na cana-de-açúcar (Fig. 1). A redução verificada pode ser explicada pela elevação do teor de matéria mineral da canade-açúcar tratada com os níveis de $\mathrm{CaO}$, o qual contribuiu para a redução do teor de CT, uma vez que matéria mineral é subtraída no cálculo dos
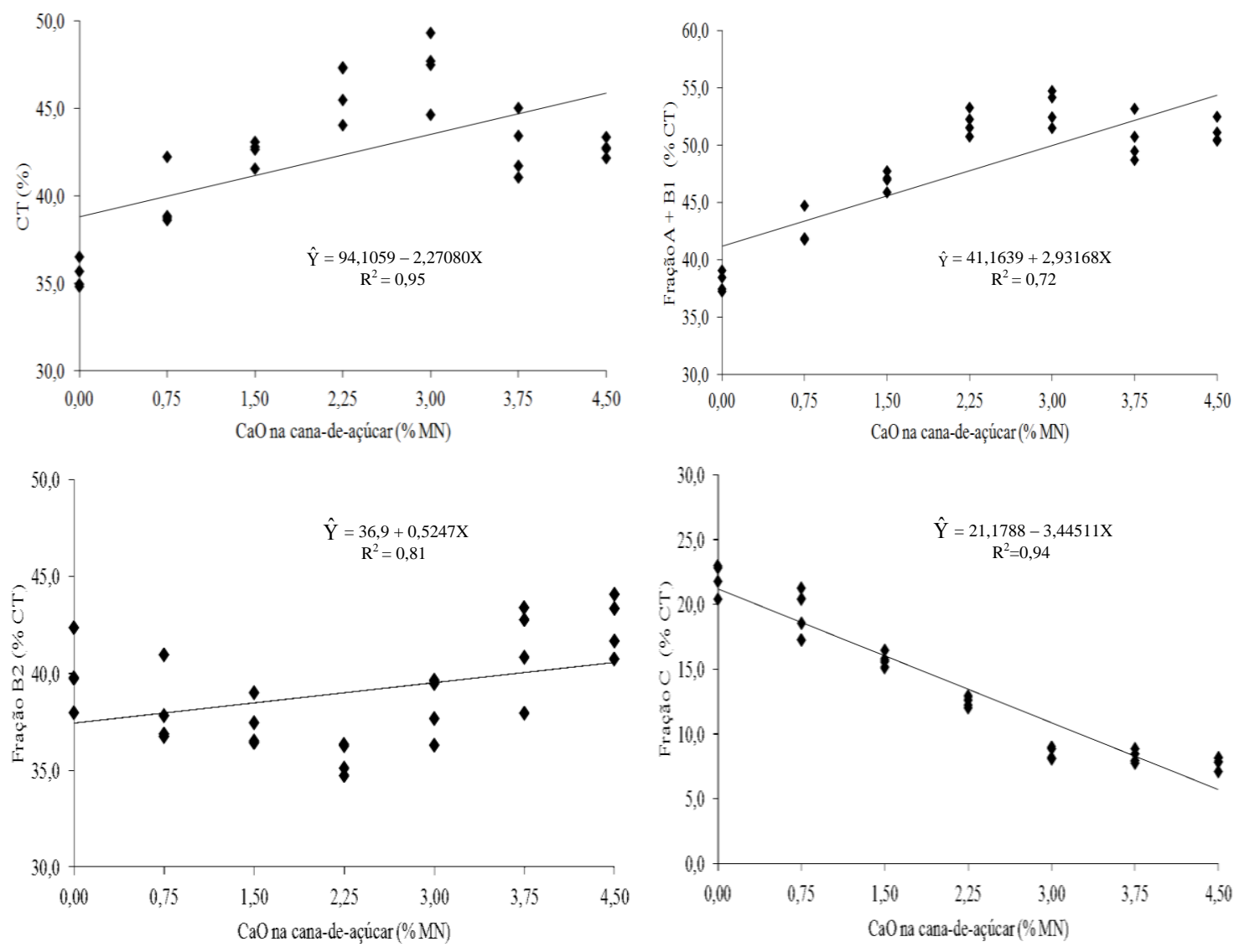

Figura 1. Teor de carboidratos totais (CT), fração A + B1, fração B2 e fração C da cana-de-açúcar tratada com diferentes porcentagens de óxido de cálcio $(\mathrm{CaO})$, em percentagem da matéria natural $(\mathrm{MN})$. 
Quanto aos carboidratos não fibrosos (fração A+B1), a cana-de-açúcar com $0 ; 0,75$ e $1,5 \%$ de $\mathrm{CaO}$ apresentou menor valor em relação à canade-açúcar in natura (Tab. 2). Já a cana-de-açúcar com os níveis de $\mathrm{CaO}$ de 2,25; 3,0; 3,75 e 4,5\% apresentou valores mais altos de $\mathrm{A}+\mathrm{B} 1 \mathrm{em}$ relação à cana-de-açúcar in natura. A possível presença de fermentação na cana-de-açúcar tratada com essas porcentagens de $\mathrm{CaO}$ pode ter contribuído para a redução do teor da fração $\mathrm{A}+\mathrm{B} 1$, pois observou-se aquecimento no material no final das 24 horas (Tab. 1), momento este em que as amostras foram coletadas para armazenamento. $\mathrm{O}$ aquecimento proveniente da fermentação pode ter provocado queima de carboidratos solúveis (açúcares) da cana-deaçúcar e, consequentemente, redução da fração $\mathrm{A}+\mathrm{B} 1$. Visto que os carboidratos não fibrosos apresentam rápida degradação ruminal, a diminuição destes na cana-de-açúcar pode ocasionar menor disponibilidade de energia para o desenvolvimento dos microrganismos ruminais.

As porcentagens mais baixas de $\mathrm{CaO}(0 ; 0,75$ e $1,5 \%)$ em relação à cana-de-açúcar in natura promoveram redução da fração $\mathrm{A}+\mathrm{B} 1$ da canade-açúcar possivelmente pela presença de fermentação no material. Os resultados estão de acordo com os encontrados por Cruz et al. (2009), que, na análise de regressão linear, mostraram que houve diminuição ( $\mathrm{Y}=39,1324$ $\left.7,91133 x \mathrm{R}^{2}=90,0\right)$ nos teores da fração $\mathrm{A}+\mathrm{B} 1$ da cana-de-açúcar para os níveis de $0 ; 0,5 ; 1,0$; e $1,5 \%$ de $\mathrm{CaO}$.

Verificou-se que a fração $\mathrm{A}+\mathrm{B} 1$ da cana-deaçúcar aumentou linearmente $(\mathrm{P}<0,05)$ em função da adição de $\mathrm{CaO}$ (Fig. 1). Tal comportamento deve-se às alterações promovidas na parede celular do material, diminuindo os componentes fibrosos. Além disso, é provável que não tenha ocorrido fermentação na cana-de-açúcar tratada a partir de $1,5 \%$ de $\mathrm{CaO}$, preservando a fração $\mathrm{A}+\mathrm{B} 1$. Essa fração é considerada uma boa fonte de energia para o desenvolvimento de microrganismos que utilizam os carboidratos não fibrosos. Porém, é necessário incrementar fontes proteicas quando a fração A+B1 compõe a principal fração de carboidratos da dieta para melhor sincronia entre a liberação de energia e nitrogênio (Valadares Filho, 2000).
A fração B2 dos carboidratos da cana-de-açúcar com $\mathrm{CaO}$ foi diferente $(\mathrm{P}<0,05)$ da cana-deaçúcar in natura (Tab. 2). Pode-se também observar o crescimento linear $(\mathrm{P}<0,05)$ dos teores dessa fração (Fig. 1) em função da porcentagem de $\mathrm{CaO}$. $\mathrm{O}$ aumento da fração B2 dos carboidratos da cana-de-açúcar tratada com $\mathrm{CaO}$ foi decorrente de possíveis alterações ocasionadas na parede celular do material, por meio da solubilização de componentes indigestíveis e disponibilização dos potencialmente digestíveis.

Os resultados observados neste estudo para a fração B2 dos carboidratos diferem dos verificados por Cruz et al. (2009), os quais obtiveram valores de 39,$6 ; 35,0 ; 30,1$ e 28,1 , respectivamente, para $0 ; 0,5 ; 1,0$ e $1,5 \%$ de $\mathrm{CaO}$ aplicados na cana-de-açúcar. No presente estudo, as porcentagens de $\mathrm{CaO}$ utilizadas no tratamento da cana-de-açúcar foram mais altos, podendo ser a causa das diferenças encontradas. Azevedo et al. (2003), ao trabalharem com diferentes variedades, encontraram valores de 25,25; 30,31 e 33,26\% de fração B2 dos carboidratos, para as variedades SP 80-1842, RB 84-5257 e SP791011, respectivamente.

Verificou-se efeito $(\mathrm{P}<0,05)$ para a fração $\mathrm{C}$ dos carboidratos, sendo os valores observados para a cana-de-açúcar com 0 e $0,75 \%$ de $\mathrm{CaO}$ semelhantes aos da cana-de-açúcar in natura. A cana-de-açúcar com 1,$5 ; 2,25 ; 3,0 ; 3,75$ e 4,5\% de $\mathrm{CaO}$ apresentaram valores de fração $\mathrm{C}$ dos carboidratos mais baixos que os da cana-deaçúcar in natura (Tab. 2). Os resultados indicam que, com a adição a partir de $1,5 \%$ de $\mathrm{CaO}$ na cana-de-açúcar, ocorre significativa redução dos componentes indigestíveis dos carboidratos. A fração $\mathrm{C}$ dos carboidratos da cana-de-açúcar diminuiu de forma linear, verificando decréscimo de 3,4 pontos percentuais para cada unidade de $\mathrm{CaO}$ utilizada (Fig. 1). A redução observada pode estar ainda relacionada com a ação do $\mathrm{CaO}$ na lignina da parede celular da cana-de-açúcar, conferindo maior digestibilidade dos carboidratos fibrosos dessa forragem.

A fração indisponível C depende do teor de lignina; portanto, plantas de idade fisiológica mais avançada apresentam maiores teores dessa fração. A redução da fração $\mathrm{C}$ dos carboidratos em volumosos melhora o aproveitamento da fração fibrosa, consequentemente aumenta a 
disponibilidade de energia da cana-de-açúcar para o ruminante. Os resultados observados no presente estudo assemelham-se aos obtidos por Cruz et al. (2009), os quais verificaram, do mesmo modo, redução linear na fração $\mathrm{C}$ dos carboidratos da cana-de-açúcar tratada com 0 ; 0,$5 ; 1,0$ e $1,5 \%$ de $\mathrm{CaO}$.

Para os parâmetros da degradabilidade ruminal, verificou-se diferença da fração $\mathrm{A}$ da $\mathrm{MS}$ $(\mathrm{P}<0,05)$, com maior valor para a cana-de-açúcar tratada com 3,0\% de $\mathrm{CaO}$. Valores semelhantes e inferiores aos demais foram observados entre a cana-de-açúcar com 0 e 4,5\% de $\mathrm{CaO}$ (Tab. 3). Os menores valores de fração A na cana-deaçúcar com 0 e 4,5\% de $\mathrm{CaO}$ decorreram de aquecimento (Tab. 1). Pressupõe-se que o aquecimento na cana-de-açúcar com $0 \%$ de $\mathrm{CaO}$ no final das 24 horas de tratamento foi devido à fermentação, provocando perdas de açúcares. Do mesmo modo, na cana-de-açúcar com 4,5\%, o aquecimento excessivo decorrente do tratamento alcalino nas primeiras horas após a adição do $\mathrm{CaO}$ pode ter ocasionado queima de carboidratos solúveis (açúcares). Ribeiro et al. (2009), ao avaliarem os parâmetros de degradação ruminal da matéria seca e dos componentes da parede celular da cana-deaçúcar tratada com hidróxido de sódio ou óxido de cálcio pela técnica in situ, também encontraram aumento em relação à cana-deaçúcar in natura nos tratamentos com $2,25 \%$ de $\mathrm{CaO}$ e $2,25 \%$ de $\mathrm{NaOH}$, apresentando os respectivos valores para fração A: 38,5; 47,5 e $54,5 \%$.

Observou-se efeito $(\mathrm{P}<0,05)$ na fração insolúvel potencialmente degradável (fração $\mathrm{B}$ ) da MS da cana-de-açúcar com os níveis de $\mathrm{CaO}$, sendo o maior valor observado para a cana-de-açúcar tratada com $4,5 \%$ de $\mathrm{CaO}$.

Tabela 3. Parâmetros da degradação ruminal da matéria seca (MS) e intervalos de confiança (LI e LS) da cana-de-açúcar tratada com óxido de cálcio $(\mathrm{CaO})$

\begin{tabular}{|c|c|c|c|c|c|c|c|c|c|}
\hline \multirow[t]{2}{*}{$\mathrm{CaO}(\%)$} & \multicolumn{3}{|c|}{$\mathrm{A}$} & \multicolumn{3}{|c|}{ B } & \multicolumn{3}{|c|}{$\mathrm{C}$} \\
\hline & Média & LI & $\mathrm{LS}$ & Média & LI & $\mathrm{LS}$ & Média & $\mathrm{LI}$ & LS \\
\hline 0 & $42,9 c$ & 41,9 & 43,8 & $22,1 d$ & 21,0 & 23,3 & $0,0245 b$ & 0,0208 & 0,0282 \\
\hline 1,5 & $47,2 \mathrm{~b}$ & 46,3 & 48,2 & $26,9 c$ & 25,8 & 28,1 & $0,0235 b$ & 0,0204 & 0,0267 \\
\hline 3,0 & $49,7 \mathrm{a}$ & 48,8 & 50,7 & $33,5 b$ & 32,3 & 34,7 & $0,0218 b$ & 0,0193 & 0,0244 \\
\hline 4,5 & $41,2 \mathrm{c}$ & 40,2 & 42,1 & $42,6 a$ & 41,6 & 43,7 & $0,0338 \mathrm{a}$ & 0,0314 & 0,0361 \\
\hline
\end{tabular}

$\mathrm{A}=$ fração solúvel (\%); $\mathrm{B}=$ fração insolúvel potencialmente degradável $(\%) ; \mathrm{C}=$ taxa fracional de degradação $\left(\mathrm{h}^{-1}\right)$; LI = limite inferior; $\mathrm{LS}=$ limite superior. Médias seguidas de letras distintas na coluna são diferentes com $95 \%$ de confiança.

Possíveis alterações ocorridas nas ligações dos carboidratos fibrosos podem ter contribuído para os resultados obtidos. Cavali et al. (2010), ao avaliarem os efeitos da adição de diferentes porcentagens de óxido de cálcio sobre a composição química, a digestibilidade in vitro, a degradabilidade in situ e as perdas de matéria seca em silagens de cana-de-açúcar, obtiveram valores com pequena variação para a fração insolúvel potencialmente degradável (B) - 23,72; 23,$32 ; 29,72 ; 26,93$ e $23,37 \%$ para as porcentagens de $0 ; 0,5 ; 1,0 ; 1,5$ e $2,0 \%$ de $\mathrm{CaO}-$ registrando-se valor médio de $25,4 \%$. O valor de fração B obtido na cana-de-açúcar tratada com $1,5 \%$ de $\mathrm{CaO}$ no presente estudo é condizente com o valor obtido por Cavali et al. (2010) quando utilizaram essa mesma porcentagem de $\mathrm{CaO}$.
A taxa fracional de degradação da MS (fração C) apresentou diferença $(\mathrm{P}<0,05)$, verificando-se maior valor para a cana-de-açúcar com $4,5 \%$ de $\mathrm{CaO}$ e valores semelhantes entre a cana-deaçúcar com $0,1,5$ e 3,0\% de $\mathrm{CaO}$, com $95 \%$ de confiança (Tab. 3). Notadamente os maiores perfis de degradação da MS (Fig. 2) foram observados para a cana-de-açúcar com os níveis mais elevados de $\mathrm{CaO}$, principalmente na canade-açúcar com 4,5\% de $\mathrm{CaO}$. Esse resultado está relacionado à melhor hidrólise da cana-de-açúcar nessa concentração. De acordo com Macedo at al. (2011), que avaliou os parâmetros de degradação ruminal da matéria seca, da fibra em detergente neutro e fibra em detergente ácido da cana-de-açúcar tratada com $\mathrm{CaO}$ nas porcentagens de $0 ; 1,0 ; 2,0$ e $3,0 \%$, os melhores resultados de degradabilidade ruminal da MS da cana-de-açúcar ocorreram com 3,0\% de $\mathrm{CaO}$. 

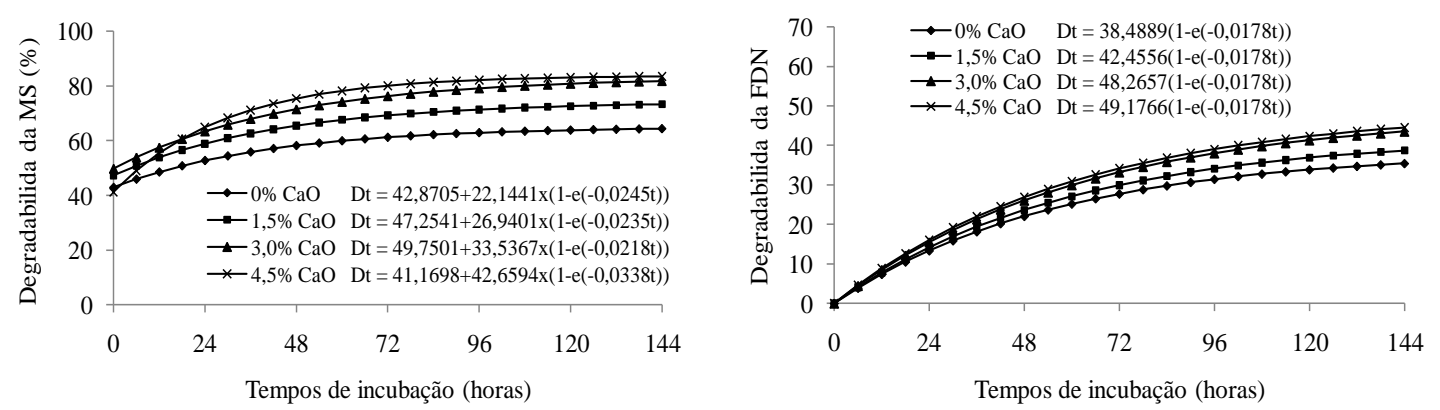

Figura 2. Degradabilidade da matéria seca (MS) da cana-de-açúcar tratada com óxido de cálcio $(\mathrm{CaO})$ nos diferentes tempos de incubação.

Para a fração insolúvel potencialmente degradável padronizada (Bp) da FDN, verificouse diferença $(\mathrm{P}<0,05)$ entre a cana-de-açúcar com os níveis de $\mathrm{CaO}$. Os maiores valores da fração Bp foram observados na cana-de-açúcar com 3,0 e 4,5\% de $\mathrm{CaO}$, os quais foram semelhantes entre si. O menor valor de $\mathrm{Bp}$ foi observado na canade-açúcar sem adição de $\mathrm{CaO}(0 \%)$.

Ribeiro et al. (2009) avaliaram os parâmetros de degradação ruminal da matéria seca e dos componentes da parede celular da cana-deaçúcar tratada com hidróxido de sódio ou óxido de cálcio pela técnica in situ e encontraram, para a fração insolúvel potencialmente degradável, em relação à cana-de-açúcar, valores maiores para os tratamentos com 2,25\% de $\mathrm{CaO}$ ou $\mathrm{NaOH}$, respectivamente, de 30,5 e $33,9 \%$. Neste estudo, os maiores valores observados em relação aos obtidos por Ribeiro et al. (2009) podem ser explicados pelas porcentagens mais altas de $\mathrm{CaO}$ utilizadas no tratamento da cana-de-açúcar.

Tabela 4. Parâmetros da degradação ruminal da fibra em detergente neutro (FDN) e intervalos de confiança (LI e LS) da cana-de-açúcar tratada com óxido de cálcio $(\mathrm{CaO})$

\begin{tabular}{|c|c|c|c|c|c|c|c|c|c|}
\hline \multirow[t]{2}{*}{$\mathrm{CaO}(\%)$} & \multicolumn{3}{|c|}{$\mathrm{Bp}$} & \multicolumn{3}{|c|}{ Ip } & \multicolumn{3}{|c|}{$\mathrm{C}$} \\
\hline & Média & LI & LS & Média & LI & LS & Média & LI & LS \\
\hline 0 & $38,4 \mathrm{c}$ & 37,0 & 39,8 & $61,5^{\mathrm{a}}$ & 60,0 & 63,1 & $0,0178 \mathrm{a}$ & 0,0159 & 0,0197 \\
\hline 1,5 & $42,4 \mathrm{~b}$ & 40,9 & 44,0 & $57,6 \mathrm{~b}$ & 56,0 & 59,3 & $0,0170 \mathrm{a}$ & 0,0152 & 0,0187 \\
\hline 3,0 & $48,2 \mathrm{a}$ & 46,7 & 49,7 & $51,8 \mathrm{c}$ & 50,3 & 53,4 & $0,0162 \mathrm{a}$ & 0,0147 & 0,0178 \\
\hline 4,5 & $49,1 \mathrm{a}$ & 47,6 & 50,7 & $50,8 \mathrm{c}$ & 49,2 & 52,5 & $0,0165 \mathrm{a}$ & 0,0150 & 0,0180 \\
\hline
\end{tabular}

$\mathrm{Bp}=$ fração insolúvel potencialmente degradável padronizada $(\%) ; \mathrm{I}_{\mathrm{p}}=$ fração indegradável padronizada $(\%) ; \mathrm{C}=$ taxa fracional de degradação $\left(\mathrm{h}^{-1}\right)$. Médias seguidas de letras distintas na coluna são diferentes com $95 \%$ de confiança.

A análise da fração indegradável padronizada (Ip) da FDN apresentou efeito significativo, com maiores valores observados para a cana-deaçúcar com 3,0 e 4,5\% de $\mathrm{CaO}$. O maior valor de Ip foi verificado na cana-de-açúcar sem adição de $\mathrm{CaO}(0 \%)$. Tudo indica que os menores valores de Ip na cana-de-açúcar com 3,0 e 4,5\% de $\mathrm{CaO}$ decorreram do efeito direto que o tratamento alcalino provocou na parede celular, refletindo em solubilização de parte dos componentes indigestíveis. Os resultados observados para Ip no presente trabalho assemelham-se aos obtidos por Carvalho et al.
(2010), que, ao tratarem a cana-de-açúcar com $\mathrm{CaO}-0 ; 0,75 ; 1,5$ e $2,25 \%$, observaram redução da fração indigestível da FDN. Cavali (2006), ao avaliar os efeitos da adição de óxido de cálcio ( 0 ; 0,$5 ; 1,0 ; 1,5$ e $2,0 \%$ na matéria natural) sobre a composição química e as perdas em silagens de cana-de-açúcar, utilizando silos laboratoriais, encontrou, ao adicionar $\mathrm{CaO}$, mais baixos teores da fração indegradável da FDN, mencionado que provavelmente está relacionado aos menores teores de FDA observados para as silagens com o aditivo. 
Os resultados da taxa fracional de degradação (fração C) da FDN da cana-de-açúcar não apresentaram efeito significativo $(\mathrm{P}<0,05)$ entre tratamentos de $\mathrm{CaO}$, evidenciando que o $\mathrm{CaO}$ não interfere na taxa fracional de degradação. Embora não exista diferença significativa nessa fração, os maiores valores de Bp e menores de Ip na cana-de-açúcar com 3,0 e 4,5\% indicam maior aproveitamento da fibra.

Observou-se que a DP da MS da cana-de-açúcar tratada com $\mathrm{CaO}$ foi de 65,$0 ; 74,1 ; 83,2$ e $83,8 \%$, respectivamente, para $0 ; 1,5 ; 3,0$ e $4,5 \%$ de $\mathrm{CaO}$ na cana-de-açúcar, considerando o tempo máximo de incubação de 144 horas. Esse mesmo comportamento foi observado para a DP da FDN, sendo os valores de 38,4; 42,4; 48,2 e $49,1 \%$ para as mesmas porcentagens de $\mathrm{CaO}$. Os resultados com maiores valores dos perfis da DP tanto da MS quanto da FDN sugerem melhor aproveitamento dos nutrientes da cana-de-açúcar quando tratada com $\mathrm{CaO}$.

A análise da DE da MS da cana-de-açúcar tratada com $\mathrm{CaO}$, independentemente da taxa de passagem $(2,0 ; 5,0$ e 8,0\%/hora), apresentou valores mais altos (Tab. 5). Apesar de o $\mathrm{CaO}$ promover melhora no aproveitamento da fibra da cana-de-açúcar, aumentando as taxas de DE, observa-se que os valores de DE da FDN nas taxas de passagens de 2 e $5 \%$ /hora são muito baixos, indicando a necessidade de elevadas quantidades de alimentos concentrados na dieta de animais ruminantes de médio e alto potencial de produção, caso a cana-de-açúcar seja utilizada como volumoso exclusivo.

Tabela 5. Degradabilidade potencial (DP) e efetiva (DE) da matéria seca (MS) e da fibra em detergente neutro (FDN) da cana-de-açúcar tratada com óxido de cálcio, calculadas para taxas de passagem de 2,5 e $8 \% / \mathrm{h}$

\begin{tabular}{|c|c|c|c|c|}
\hline \multirow{2}{*}{ Parâmetro } & \multicolumn{4}{|c|}{ Óxido de cálcio (\% MN) } \\
\hline & 0 & 1,5 & 3,0 & 4,5 \\
\hline & \multicolumn{4}{|c|}{$\mathrm{MS}(\%)$} \\
\hline DP & 65,0 & 74,1 & 83,2 & 83,8 \\
\hline $\operatorname{DE}\left(0,02 \mathrm{~h}^{-1}\right)$ & 55,1 & 61,7 & 67,2 & 68,0 \\
\hline $\operatorname{DE}\left(0,05 \mathrm{~h}^{-1}\right)$ & 50,2 & 55,8 & 59,9 & 58,4 \\
\hline $\operatorname{DE}\left(0,08 \mathrm{~h}^{-1}\right)$ & 48,1 & 53,3 & 56,9 & 53,8 \\
\hline \multicolumn{5}{|c|}{ FDN $(\%)$} \\
\hline DP & 38,4 & 42,4 & 48,2 & 49,1 \\
\hline $\operatorname{DE}\left(0,02 \mathrm{~h}^{-1}\right)$ & 18,1 & 19,5 & 21,5 & 22,2 \\
\hline $\operatorname{DE}\left(0,05 \mathrm{~h}^{-1}\right)$ & 10,1 & 10,8 & 11,8 & 12,2 \\
\hline $\operatorname{DE}\left(0,08 \mathrm{~h}^{-1}\right)$ & 7,0 & 7,4 & 8,1 & 8,4 \\
\hline
\end{tabular}

Os resultados de DE observados neste estudo estão de acordo com os observados por Ribeiro et al. (2009), que avaliaram os parâmetros de degradação ruminal da matéria seca e da fração fibrosa da cana-de-açúcar tratada com hidróxido de sódio ou óxido de cálcio pela técnica in situ.

\section{CONCLUSÕES}

Porcentagens de óxido de cálcio a partir de 1,5\% na cana-de-açúcar promovem aumento da fração solúvel e da fração disponível da fibra e reduzem a fração indigestível. A adição de 3,0 e 4,5\% de óxido de cálcio na cana-de-açúcar promove melhores taxas de degradação ruminal tanto da matéria seca quanto da fibra em detergente neutro.

\section{AGRADECIMENTOS}

À Fundação de Amparo à Pesquisa do Estado da Bahia (FAPESB) pela concessão da bolsa de estudos durante o mestrado. 


\section{REFERÊNCIAS}

AZEVEDO, J.A.G.; PEREIRA, J.C.; QUEIROZ, A.C. et al. Composição químico-bromatológica, fracionamento de carboidratos e cinética da degradação in vitro da fibra de três variedades de cana-de-açúcar (Saccharum spp.). Rev. Bras. Zootec., v.32, p.1443-1453, 2003.

BALIEIRO NETO, G.; SIQUEIRA, G.R.; REIS, R.A. et al. Óxido de cálcio como aditivo na ensilagem de cana-de-açúcar. Rev. Bras. Zootec., v.36, p.1231-1239, 2007.

CABRAL, L.S.; VALADARES FILHO, S.C.; DETMANN, E. et al. Taxas de digestão das frações proteicas e de carboidratos para as silagens de milho e de capim-elefante, o feno de capim-tifiton- 85 e o farelo de soja. Rev. Bras. Zootec., v.33, p.1573-1580, 2004.

CARVALHO, G.G.P.; CAVALI, J.; FERNANDES, F.E.P. et al. Composição química e digestibilidade da matéria seca do bagaço de cana-de-açúcar tratado com óxido de cálcio. Arq. Bras. Med. Vet. Zootec., v.61, p.1346-1352, 2009.

CARVALHO, G.G.P.; PIRES, A.J.V.; VELOSO, C.M. et al. Valor nutritivo do bagaço de cana-deaçúcar amonizado com quatro doses de ureia. Pesq. Agrop. Bras., v.41, p.125-132, 2006.

CARVALHO, G.G.P.; RASMO, G.; PIRES, A.J.V.; SILVA, R.R.; PEREIRA, M.L.A.; VIANA, P.T.; SANTOS, A.B.; PEREIRA, T.C. Balanço de nitrogênio, concentrações de uréia e síntese de proteína microbiana em caprinos alimentados com dietas contendo cana-de-açúcar tratada com óxido de cálcio. Revista Brasileira de Zootecnia, v.39, n.10, p.2253-2261, 2010.

CAVALI, J. Cana-de-açúcar ensilada com óxido de cálcio, capim-elefante ou inoculante bacteriano. 2006, 60f. Dissertação (Mestrado em Zootecnia) Universidade Federal de Viçosa, UFV, Viçosa, 2006.

CAVALI， J.; PEREIRA， O.G.; VALADARES FILHO, S.C. et al. Bromatological and microbiological characteristics of sugarcane silages treated with calcium oxide. Rev. Bras. Zootec., v.39, p.1398-1408, 2010.

CRUZ, B.C.C.; SCHIO, A.R.; PIRES, A.J.V. et al. Parâmetros físico-químicos e fracionamento de carboidratos da cana-de-açúcar submetida a diferentes concentrações de óxido de cálcio. PUBVET, v.3, n.6, 2009.
DOMINGUES, F.N.; OLIVEIRA, M.D.S.; MOTA, D.A. et al. Parâmetros bromatológicos da cana-deaçúcar tratada com níveis crescentes de cal virgem $(\mathrm{CaO})$ microprocessada em diferentes tempos de exposição ao ar. In: REUNIÃO ANUAL DA SOCIEDADE BRASILEIRA DE ZOOTECNIA, 44., 2007, Jaboticabal. Anais... Jaboticabal: Sociedade Brasileira de Zootecnia, 2007. (CD - ROM).

DUNNETT, C.W. A multiple comparison procedure for comparing several treatments with control. J. Am. State Associat., v.50, p.1096-1121, 1955.

FERNANDES, A.M.; QUEIROZ, A.C.; ANA, R.P. et al. Estimativas da produção de leite por vacas holandesas mestiças, segundo o sistema CNCPS, em dietas contendo cana-de-açúcar com diferentes valores nutritivos. Rev. Bras. Zootec., v.30, p.1350-1357, 2001.

HALL, M.B. Challenges with nonfiber carbohydrate methods. J. Anim. Sci., v.81, p.3226-3232, 2003.

MACEDO, T.M.; PIRES, A.J.V.; CARVALHO, G.G.P. et al. Degradabilidade da matéria seca e da fração fibrosa da cana de açúcar tratada com óxido de cálcio. Rev. Bras. Saúde Prod. An., v.12, n.2, p.429440, 2011.

MERTENS, D.R.; LOFTEN, J.R. the effects of starch on forage fiber digestion kinetics in vitro. J. Dairy Sci., v.63, p.1437-1446, 1980 .

NRC-NATIONAL RESEARCH COUNCIL. Nutrient requirements of dairy cattle. 7.ed. Washington: National Academy Press, p.450, 2001.

NOCEK, J.E. In situ and other methods to estimate ruminal protein and energy digestibility: a review. $J$. Dairy Sci., v.71, p.1052-1069, 1988.

OLIVEIRA, M.D.S.; BODRICK. R.; SANTOS, J. et $a l$. Efeito da hidrolise com cal hidratada (hidróxido de cálcio) sobre a digestibilidade "in vitro" da cana-deaçúcar (Saccharum officinarum L.). In: REUNIÃO ANUAL DA SOCIEDADE BRASILEIRA DE ZOOTECNIA, 43., 2006, João Pessoa, PA. Anais... João Pessoa:SBZ. 2006. (CD ROM).

ØRSKOV, E.R.; McDONALD, I. The estimation of protein degradability in the rumen from incubation measurements of feed in weighted according to rate passage. J. Agricult. Sci., v.92, p.499-503, 1979.

RIBEIRO, L.S.O; PIRES, A.J.V.; CARVALHO, G.G.P.; CHAGAS, D.M.T. Degradabilidade da matéria seca e da fração fibrosa da cana-de-açúcar tratada com hidróxido de sódio ou óxido de cálcio. Rev. Bras. Saúde Prod. Anim., v.10, p.573-585, 2009. 
SILVA, R.A.; CACERE, E.R.; DIAS, A.C.S. et al. Efeito da adição de cal hidratada na cana-de-açúcar picada sobre a composição química e digestibilidade in vitro da matéria seca. In: REUNIÃO ANUAL DA SOCIEDADE BRASILEIRA DE ZOOTECNIA, 43., 2006, João Pessoa. Anais... Paraíba: Sociedade Brasileira de Zootecnia, 2006. (CD-ROM).

SILVA, D.J.; QUEIROZ, A.C. Análises de alimentos (métodos químicos e biológicos). 3.ed. Viçosa, MG: Editora UFV, 2002. p.235.

SILVA, T.M.; OLIVEIRA, M.D.S.; SAMPAIO, A.A.M. et al. Efeito da hidrólise de diferentes variedades de cana-de-açúcar sobre a digestibilidade ruminal "in vitro". In: REUNIÃO ANUAL DA SOCIEDADE BRASILEIRA DE ZOOTECNIA, 42. ., 2005, Goiânia. Anais... Goiânia: Sociedade Brasileira de Zootecnia, 2005. (CD-ROM).
TEIXEIRA JÚNIOR, D.J.; OLIVEIRA, M.D.S.; MOTA, D.A. et al. Efeito da cal virgem (óxido de cálcio) como agente hidrolisante sobre a composição bromatológica da cana-de-açúcar após 24 horas de tratamento. In: REUNIÃO ANUAL DA SOCIEDADE BRASILEIRA DE ZOOTECNIA, 44., 2007, Jaboticabal. Anais... Jaboticabal: Sociedade Brasileira de Zootecnia, 2007. (CD-ROM).

VALADARES FILHO, S.C. Nutrição, avaliação de alimentos e tabelas de composição de alimentos para bovinos. In: REUNIÃO ANUAL DA SOCIEDADE BRASILEIRA DE ZOOTECNIA, 37., 2000. Viçosa, MG. Anais... Viçosa, MG: Sociedade Brasileira de Zootecnia, 2000. (CD-ROM).

WALDO, D.R.; SMITH, L.W.; COX, E.L. Model f cellulose disappearance from the rumen. J. Dairy Sci., v.55, p.125-129, 1972. 